\title{
Anabases
}

ANABASES Traditions et réceptions de l'Antiquité

$16 \mid 2012$

Varia

\section{Luba FREEDMAN, The Revival of the Olympian Gods in Renaissance Art}

Adeline Grand-Clément

\section{OpenEdition}

\section{Journals}

Édition électronique

URL : http://journals.openedition.org/anabases/4054

DOI : 10.4000/anabases.4054

ISSN : 2256-9421

\section{Éditeur}

E.R.A.S.M.E.

\section{Édition imprimée}

Date de publication : 1 octobre 2012

Pagination : 336-338

ISSN : 1774-4296

\section{Référence électronique}

Adeline Grand-Clément, «Luba freEdman, The Revival of the Olympian Gods in Renaissance Art », Anabases [En ligne], 16 | 2012, mis en ligne le 01 octobre 2012, consulté le 22 septembre 2020. URL: http://journals.openedition.org/anabases/4054 ; DOI : https://doi.org/10.4000/anabases.4054

Ce document a été généré automatiquement le 22 septembre 2020.

(c) Anabases 


\title{
Luba FREEDMAN, The Revival of the Olympian Gods in Renaissance Art
}

\author{
Adeline Grand-Clément
}

\section{RÉFÉRENCE}

Luba FREEDMAN, The Revival of the Olympian Gods in Renaissance Art, Cambridge, Cambridge University Press, 2003 (Hardback), 2010 (Paperback), 301 p.+, 78 ill.

85 dollars / isbn 0-521-81576-2.

1 On sait depuis l'ouvrage de J. Seznec (La survivance des dieux antiques, 1939) que les hommes de la Renaissance n'ont pas redécouvert les divinités du panthéon grécoromain. Ces dernières n'ont cessé d'occuper une place dans l'imaginaire et la culture de l'Occident médiéval depuis la fin de l'Antiquité. Mais, d'après L. Freedman, la nouveauté $\mathrm{du} \mathrm{XvI} \mathrm{I}^{\mathrm{e}}$ siècle italien réside dans le mode de représentation qui est alors adopté : peintres, sculpteurs et graveurs figurent désormais les puissances olympiennes « all'antica». Les dieux païens retrouvent alors leurs attributs, dans des mises en scène qui tendent à leur redonner leur splendeur et leur majesté antiques. Or la prolifération de telles images sculptées ou peintes dans l'espace public (jusqu'au début du XVII ${ }^{e}$ siècle) ne va pas sans poser problème, dans un contexte où artistes, commanditaires et public appartiennent tous à la communauté chrétienne. L'ouvrage de L. Freedman, initialement paru en 2003 et republié en 2010, s'emploie à mettre en lumière les enjeux d'un tel phénomène. L'auteur, professeur à l'université hébraïque de Jérusalem, est spécialiste de l'art italien des $\mathrm{Xv}^{\mathrm{e}}$ et $\mathrm{XVI}^{\mathrm{e}}$ siècles et vient de publier une étude sur la réception de la mythologie gréco-romaine dans la peinture de la Renaissance italienne (Classical Myths in Italian Renaissance Painting, 2011). Dans The Revival of the Olympian Gods in Renaissance Art, L. Freedman s'emploie à démontrer que, pour rendre acceptable les «épiphanies » de dieux païens, les artistes s'inspirent des œuvres antiques mais y ajoutent des éléments empruntés à leur propre époque : ils parviennent ainsi à rendre acceptables les Olympiens, à neutraliser le pouvoir de ces «faux dieux». Les images 
peintes, sculptées ou gravées ainsi créées sont alors appréhendées d'un point de vue esthétique ou allégorique, et non plus en tant que figurations de puissances surnaturelles.

2 L'ouvrage comporte neuf chapitres, répartis au sein de trois parties. La première, assez courte, présente les notions clefs utilisées pour l'analyse et précise les contours du phénomène étudié. L'auteur justifie d'abord le choix de limiter l'étude au groupe des "dieux olympiens", à savoir ceux qui occupent le sommet du panthéon gréco-romain. Elle précise ensuite qu'elle n'étudie que les « représentations autonomes » des divinités en question. Elle entend par là un mode de figuration spécifique, où le sujet est représenté seul, ou dans une attitude indépendante des personnages qui l'accompagnent, donc en position d'autorité. L'auteur exclut ainsi de son analyse toutes les scènes à caractère narratif, dans lesquelles les figures seraient engagées physiquement ou émotionnellement dans une action - on pense à tous les épisodes mythologiques, abondamment représentés dans l'art italien de la Renaissance, et qui ont fait l'objet de l'ouvrage paru en 2011. Le deuxième chapitre insiste ensuite sur les motivations des acteurs - artistes et commanditaires. L'auteur montre que la représentation des Olympiens en majesté sert plusieurs objectifs: recherche de l'excellence artistique, effort de légitimation de l'autorité, moyen de reconnaissance sociale.

3 La deuxième partie revient sur le rôle joué par certains artefacts antiques dans la connaissance que les artistes italiens pouvaient avoir des dieux grecs et romains au $\mathrm{XVI}^{\mathrm{e}}$ siècle. Statues, monnaies et gemmes offraient des témoignages iconographiques précieux et ont contribué, aux côtés des sources littéraires, à enrichir la compréhension du fonctionnement du panthéon classique, à préciser l'identité de chaque divinité, et finalement à nourrir de nouveaux types de figuration. Ce sont ces œuvres d'art produites dans l'Italie du XVI ${ }^{\mathrm{e}}$ siècle qui font l'objet de la troisième partie. L'auteur montre comment les artistes ont composé les images des dieux, par l'association d'éléments «classiques » et "non classiques». L'un des changements les plus importants par rapport à l'Antiquité concerne la figuration des déesses : elles sont figurées nues, de manière à mettre en valeur la plasticité de leurs formes et la valeur esthétique de leur corps. Le dernier chapitre du volume insiste sur la réception ambivalente des œuvres, entre accueil favorable et réactions de défiance, voire de rejet, face à la renaissance $\mathrm{d}^{\prime}$ « idoles ", et montre comment leur production décline à la fin du $\mathrm{xVI}^{\mathrm{e}}$ siècle.

4 L'ouvrage a le mérite de mettre en lumière l'importance de ce laboratoire qu'a été l'art italien de la Renaissance dans la transmission et la réélaboration de l'héritage antique. Les problèmes abordés se situent à la croisée entre histoire de l'art, anthropologie culturelle et sociale, histoire de l'archéologie et histoire des religions. L'index, fort utile, témoigne d'ailleurs de la richesse et de la diversité des sujets traités. L'ouvrage permet notamment de mesurer la progression de la connaissance que les artistes, les érudits et les antiquaires acquièrent à cette époque de la religion et des arts des Grecs et des Romains. L'auteur éclaire aussi le processus par lequel la statue «classique " devient une sorte d'icône, symbole de l'excellence artistique et objet de contemplation esthétique. Un nouveau statut est aussi donné aux sources numismatiques, considérées comme des documents historiques, susceptibles d'enrichir les informations fournies par les textes sur la religion des Anciens. 
5 Si l'ouvrage brasse une matière riche et intéressante, il soulève des questions d'ordre méthodologique, liées à la pertinence des notions employées. Premièrement, la catégorie des "dieux olympiens » est une invention moderne, du début du XIX siècle, comme le reconnait l'auteur : elle n'est réellement opératoire ni pour l'Antiquité, ni même pour la Renaissance. Car à bien examiner les exemples d'œuvres mentionnées, on s'aperçoit que les artistes italiens ont représenté toute une série de divinités, ainsi que des héros, comme Hercule, sans établir de véritable hiérarchie. Deuxièmement, la notion de « représentation autonome » des dieux, inventée par l'auteur, recouvre une réalité mouvante. Lorsque L. Freedman parle de l'Antiquité, elle semble avoir en tête les effigies divines qui font l'objet d'un culte. Or ce n'était pas le cas de toutes les images des dieux. De plus, sur les vases grecs coexistent les deux modes de représentation (tantôt une seule divinité est représentée, en majesté et dotée de tous ses attributs; tantôt elle est engagée dans une scène à caractère narratif) : or l'auteur n'y fait jamais référence. Est-ce à dire que la céramique peinte ait été totalement ignorée des artistes italiens?

6 Enfin, en traitant la religion antique en bloc - comme si Grecs et Romains partageaient les mêmes conceptions et représentations du divin -, l'auteur adopte délibérément le point de vue des artistes et érudits du $\mathrm{XvI}^{\mathrm{e}}$ siècle. Mais il aurait peut-être été utile d'introduire tout de même quelques nuances, en tenant compte des évolutions et de la variété du statut de l'image divine, entre Grecs et Romains. Ces derniers n'ont-ils d'ailleurs pas ouvert la voie aux hommes de la Renaissance, en rassemblant dans leurs riches villas des originaux et des copies des statues d'un Praxitèle ou d'un Lysippe?

\section{AUTEURS}

\section{ADELINE GRAND-CLÉMENT}

Université de Toulouse (UTM)

adelinegc@yahoo.fr 